\title{
Revista Brasileira de Medicina de Família e Comunidade: perspectivas e desafios para 2015
}

\author{
Brazilian Journal of Family and Community Medicine: prospects and challenges for 2015
}

Revista Brasileña de Medicina Familiar y Comunitaria: perspectivas y retos para 2015

Michael Schmidt Duncan. Secretaria Municipal de Saúde do Rio de Janeiro. Rio de Janeiro, RJ, Brasil. msduncan81@gmail.com (Autor correspondente) Armando Henrique Norman. Durham University, Anthropology Department. Durham, UK. ahnorman@hotmail.com

Leonardo Ferreira Fontenelle. Universidade Federal de Pelotas (UFPel). Pelotas, RS, Brasil. leonardo@leonardof.med.br

É com muita satisfação que publicamos o número 34, volume 10, da Revista Brasileira de Medicina de Família e Comunidade (RBMFC), inaugurando o ano de 2015. A partir deste número, estamos indexados na base LILACS de forma condicional, a decisão final estando dependente dos próximos dois números da revista. Para consolidar essa conquista e buscar novas indexaçôes, estaremos ao longo deste ano implementando novas melhorias, como reformulação do corpo editorial, qualificação do processo de revisão por pares, aumento do número de artigos publicados, adaptaçôes no layout, criação de novas seçōes (p.ex., resenhas e clube de revista) e publicação 'Online First' (disponibilização online dos artigos após sua aprovação, antes de sua efetiva publicação). Essa iniciativa visa dar mais dinamismo ao periódico e sintonizar com as tendências internacionais de produção de artigos científicos. Assim, a RBMFC passará a publicar os artigos aprovados pelo corpo editorial de forma mais continuada na medida em que os artigos tenham seus processos de editoração finalizados. Desse modo, a edição trimestral será composta pela seleção do conjunto de artigos já publicados. Os PDFs dos artigos passarão a estar disponíveis no website www.rbmfc.org.br com links para os artigos online. Estamos dessa forma buscando garantir um fluxo de publicação mais contínuo dos temas mais pesquisados na área da Atenção Primária à Saúde e medicina de família. Cada artigo online possui um identificador único, ou DOI. Este identificador deve ser usado ao serem citados quaisquer artigos publicados pela RBMFC. A forma da citação, como no exemplo a seguir http://dx.doi.org/10.5712/ rbmfc10(34)1111 aparece em todos os artigos já publicados pela RBMFC. No entanto, a revista não fará mais a numeração continuada de páginas que impossibilitava tal adequação ao dinamismo exigido atualmente pelos periódicos científicos. Essas inovaçóes ocorrerão de forma gradual ao longo deste ano.

Os médicos de família e comunidade Gustavo Gusso e Paulo Poli assumirão como os editores-chefes, contribuindo com sua bagagem clínica, de gestão e de ensino universitário. Passaremos também a contar com um maior número de editores associados, para acelerar e qualificar o processo de revisão por pares. Além disso, a Associação Brasileira de Editores Científicos (ABEC), à qual a RBMFC é filiada, firmou acordo com o sistema iThenticate, o que permitirá que todos os artigos submetidos à revista passem por avaliação quanto ao teor de plágio.

Neste número, aumentamos a proporção de artigos originais e revisôes sistemáticas, contando com 7 artigos originais e 2 revisôes sistemáticas. Os temas são variados, refletindo o amplo escopo da nossa especialidade e do campo da Atenção Primária à Saúde (APS). Os temas dos artigos originais incluem: Medicina Centrada na Pessoa; associação entre depressão e hiperutilização de serviços de saúde; percepções dos profissionais de saúde sobre a Estratégia Saúde da Família; acolhimento e Núcleo de Apoio à Saúde da Família; conhecimento na comunidade sobre parasitoses intestinais; conhecimentos dos agentes comunitários de saúde sobre crack e outras drogas; e associação entre risco familiar e saúde bucal. As revisóes sistemáticas abordam o burnout de médicos da APS e a produção científica sobre avaliação na APS no Brasil. Publicamos também um ensaio que descreve o modelo de acompanhamento do pré-natal e do parto de risco habitual por obstetrizes na Inglaterra e propôe sua adaptação para a realidade brasileira, bem como um relato de dois casos clínicos sobre fluorose dentária e um 
relato de experiência sobre o uso de metodologias ativas no ensino da medicina de família e comunidade na graduação. A entrevista deste número é com o subsecretário geral de saúde do Rio de Janeiro, José Carlos Prado Jr, em que este relata as estratégias utilizadas pelo município para aumentar o número de vagas de residência em Medicina e Família e Comunidade efetivamente ocupadas. Por fim, inauguramos neste número uma seção de resenhas de livros relevantes para a nossa prática clínica, abordando desta vez o livro Estratégias da Medicina Preventiva, de Geoffrey Rose.

Desejamos a todos uma boa leitura!

Michael Schmidt Duncan Armando Henrique Norman Leonardo Ferreira Fontenelle

Editores 